\title{
Combined oridonin with cetuximab treatment shows synergistic anticancer effects on laryngeal squamous cell carcinoma: Involvement of inhibition of EGFR and activation of reactive oxygen species-mediated JNK pathway
}

\author{
SHIJIE CAO ${ }^{1,2}$, MEIJUAN XIA ${ }^{1}$, YIWEI MAO ${ }^{1,2}$, QIANG ZHANG $^{2}$, \\ PAUL OWUSU DONKOR ${ }^{3}$, FENG QIU ${ }^{1,3}$ and NING KANG ${ }^{2}$ \\ ${ }^{1}$ Department of Natural Products Chemistry, School of Traditional Chinese Materia Medica, Key Laboratory \\ of Structure-Based Drug Design and Discovery, Ministry of Education, Shenyang Pharmaceutical University, \\ Shenyang, Liaoning 110016; ${ }^{2}$ School of Integrative Medicine, Tianjin University of Traditional Chinese \\ Medicine, Tianjin 300193; ${ }^{3}$ School of Chinese Materia Medica, Tianjin State Key Laboratory of Modern \\ Chinese Medicine and Tianjin University of Traditional Chinese Medicine, Tianjin 300193, P.R. China
}

Received June 13, 2016; Accepted August 30, 2016

DOI: 10.3892/ijo.2016.3696

\begin{abstract}
Epidermal growth factor receptor (EGFR), a transmembrane glycoprotein, is expressed at high levels in a large proportion of laryngeal squamous cell carcinoma (LSCC). Cetuximab (Cet), an anti-EGFR monoclonal antibody, has limited clinical outcome for patients with head and neck squamous cell carcinoma. Our previous studies showed that oridonin (ORI), a natural and safe kaurene diterpenoid isolated from Rabdosia rubescens, inhibited cell growth in HEp-2 cells through inhibition of EGFR phosphorylation. The aim of the present study was to determine whether ORI could improve the anticancer efficacy of Cet on LSCC. We observed that the combination with Cet and ORI synergistically inhibited cell growth associated with Fas-mediated apoptosis and G2/M phase arrest in two LSCC cell lines (HEp-2 and Tu212 cells). Moreover, combination treatment caused cell death associated with suppression of p-EGFR and activation of reactive oxygen species (ROS)-mediated JNK pathway. In nude mice bearing HEp-2 xenografts, ORI plus Cet caused a significant
\end{abstract}

Correspondence to: Professor Feng Qiu, Department of Natural Products Chemistry, School of Traditional Chinese Materia Medica, Key Laboratory of Structure-Based Drug Design and Discovery, Ministry of Education, Shenyang Pharmaceutical University, Shenyang, Liaoning 110016, P.R. China

E-mail: fengqiu20070118@163.com

Professor Ning Kang, School of Integrative Medicine, Tianjin University of Traditional Chinese Medicine, Tianjin 300193, P.R. China

E-mail: kangndd@163.com

Key words: cetuximab, oridonin, epidermal growth factor receptor, laryngeal squamous cell carcinoma, synergistic anticancer effects, ROS-mediated JNK pathway tumor regression through induction of apoptosis and inhibition of proliferation with no side-effect. Together, our findings suggest that the combination of ORI and Cet has the potential to enhance tumor responses and may significantly improve therapeutic outcomes in LSCC.

\section{Introduction}

Head and neck cancers consistently rank among the six most frequently diagnosed types of cancer in the world (1). Over $90 \%$ of head and neck cancers are squamous cell carcinomas (2). Laryngeal squamous cell carcinoma (LSCC) is a common type of head and neck malignancy worldwide. Despite the advance in the conventional therapies, the overall survival rate for LSCC has not significantly improved (3). Epidermal growth factor receptor (EGFR) is a member of the HER tyrosine kinase growth factor receptor family and is invariably involved in signaling pathways affecting cellular growth, differentiation and proliferation (4). It has been well established that overexpression of EGFR promotes tumor growth and progression, including maturation, angiogenesis, invasion, metastasis and inhibition of apoptosis (5). Several research groups have confirmed that LSCC shows significantly higher EGFR expression compared with normal epithelium (6). Our group had also detected the EGFR gene amplification in human laryngeal squamous carcinoma HEp-2 cells and in 11 laryngeal carcinoma tissues by fluorescence in situ hybridization (FISH) $(7,8)$. High expression levels of EGFR contribute to oncogenesis and tumor progression in LSCC (9). Taken together, these reports indicate that EGFR is a promising target for LSCC.

Cetuximab (Cet) is a mouse-human chimeric anti-EGFR monoclonal antibody. Cet binds specifically to the extracellular domain of EGFR and induces an internalization of the receptor leading to downregulation of EGFR (10). Cet has been shown to inhibit the proliferation of a variety of cultured 
malignant human cell lines that overexpress EGFR $(11,12)$. In 2004, Cet was approved as an intravenous infusion for the treatment of head and neck cancers by the United States Food and Drug Administration (FDA) (13). However, Cet when used as a single agent exhibits limited efficacy with lower response rates $(<15 \%)$ in head and neck squamous cell carcinoma (HNSCC) patients (14). It is, therefore, essential to benchmark antitumor activity against the data accumulated with Cet when given as part of a doublet or triplet combination (15).

Anticancer agents derived from herbs and plants continue to attract attention globally due to their purported better efficiency. Rabdosia rubescens, the widely used herb in traditional Chinese medicine, is shown to suppress tumor progression, prolong survival and has low adverse effect in patients with esophageal, gastric and hepatic carcinoma $(16,17)$. Oridonin (ORI) (Fig. 1A), a natural kaurene diterpenoid, is an essential antitumor component from Rabdosia rubescens. ORI exhibits significant antitumor activity in a variety of cancer cells $(18,19)$ and has low cytotoxicity against normal cells and tissues $(20,21)$. Our previous studies also showed that ORI inhibits cell growth in HEp-2 cells through suppression of EGFR expression (22). Since combination of Cet with other cytotoxic drugs could be an effective management for HNSCC, it would be interesting to delineate and characterize the antitumor effects of the combined treatment with Cet and ORI on LSCC cells.

In the present study, we show that combination of ORI with Cet at lower doses synergistically increased the antitumor effects in LSCC cells as compared with either single agent. Furthermore, our results demonstrated that ORI plus Cet significantly induced apoptosis and cell cycle arrest in vitro and in vivo through inhibition of EGFR phosphorylation and activation of ROS-mediated JNK signaling pathway.

\section{Materials and methods}

Reagents. Cet was obtained from Merck KGaA (Darmstadt, Germany). ORI was obtained from the Beijing Institute of Biological Products (Beijing, China). RPMI-1640 medium and fetal bovine serum (FBS) were obtained from Gibco-BRL (Gaithersburg, MD, USA). The primary antibodies for western blotting and immunohistochemical studies were purchased from Cell Signaling Technology (Beverly, MA, USA). All of the other chemicals were purchased from Sigma-Aldrich (St. Louis, MO, USA).

Cell culture. HEp-2 and Tu212 cells were obtained from the American Type Culture Collection (ATCC; Manassas, VA, USA). Cell lines were maintained at $37^{\circ} \mathrm{C}$ and $5 \% \mathrm{CO}_{2}$ in RPMI-1640 medium supplemented with $10 \% \mathrm{FBS}$ and $10 \mu \mathrm{g} / \mathrm{ml}$ streptomycin and $100 \mu \mathrm{g} / \mathrm{ml}$ penicillin.

Cell viability assay. Cell viability of ORI and Cet on LSCC cells were measured by MTT assay. HEp-2 and Tu 212 cells were seeded onto 96-well culture plates at a density of 0.5 and $1 \times 10^{4}$ cells/well. Following treatment with the indicated concentrations of ORI (12, 24 and $36 \mu \mathrm{M})$ and/or Cet (1, 10 and $100 \mu \mathrm{g} / \mathrm{ml}$ ) for 24 and $48 \mathrm{~h}$, the cells were washed twice with PBS. Subsequently, MTT was then added at a final concentration of $0.5 \mu \mathrm{g} / \mathrm{ml}$, and the cells were further incubated for $2.5 \mathrm{~h}$. The medium was removed, and the formazan crystals were dissolved in dimethyl sulfoxide (DMSO) $(150 \mu \mathrm{l})$. The optical density (OD) was measured at $490 \mathrm{~nm}$ using a microplate reader (BioTek Laboratories, Winooski, VT, USA). The percentage of cell viability was calculated as follows: Cell viability $(\%)=\left[\left(\mathrm{A}_{490, \text { sample }}-\mathrm{A}_{490, \text { blank }}\right) /\left(\mathrm{A}_{490, \text { control }}-\mathrm{A}_{490, \text { blank }}\right)\right]$ $\mathrm{x} 100$.

The combined effects of ORI and Cet on cell growth inhibition were analyzed using the software CalcuSyn (Biosoft, Ferguson, MO, USA), which applies the median-effect equation of Chou and the $\mathrm{CI}$ (combination index) equation of Chou and Talalay (23).

Fluorescence microscopy examination. The apoptotic nuclear morphology was assessed by staining the cells with the fluorescent DNA-binding dye acridine orange (AO). After treatment with ORI and/or Cet for $48 \mathrm{~h}, \mathrm{LSCC}$ cells were stained with $20 \mu \mathrm{g} / \mathrm{ml} \mathrm{AO}$ for $15 \mathrm{~min}$, and then the nuclear morphology was observed under a fluorescence microscope (Olympus, Tokyo, Japan).

Flow cytometric analysis of apoptosis and cell cycle distribution. Cell apoptosis was analyzed using an Annexin V-PE/7-AAD apoptosis kit (BD Biosciences, San Diego, CA, USA) according to the manufacturer's instructions. After treatment with ORI and/or Cet for $48 \mathrm{~h}$, LSCC cells were washed with binding buffer and centrifuged. The cell pellet was resuspended in binding buffer, and $5 \mu \mathrm{l}$ Annexin-V-PE and $5 \mu 1$ 7-AAD were added, mixed, and the preparation was incubated for $15 \mathrm{~min}$ in the dark at room temperature. The apoptotic cells were measured using a BD FACSCalibur flow cytometer (Becton-Dickinson, Franklin Lakes, NJ, USA).

To evaluate the cell cycle distribution, LSCC cells were treated with ORI and/or Cet for $48 \mathrm{~h}$. Cell cycle distribution was conducted according to a previous report (22). All data were recorded and analyzed using the FlowJo software version 7.6 (Tree Star, Inc., Ashland, OR, USA).

Detection of intracellular ROS accumulation. Intracellular ROS accumulation was monitored using DCF-DA, which is a specific probe for the presence of hydrogen peroxide. The experiments were conducted by flow cytometry as previously described (24).

HEp-2 xenografts in nude mice. All of the experimental procedures were approved, and the mice were maintained and treated in accordance with the institutional guidelines of Animal Care and Use Committee of Tianjin International Joint Academy of Biotechnology and Medicine. Six-to-eight-week-old female $\mathrm{BALB} / \mathrm{c}$ athymic $\left(\mathrm{nu}^{+} / \mathrm{nu}^{+}\right)$mice were purchased from Vital River Laboratories, Co., Ltd. (Beijing, China). Logarithmically growing HEp-2 cells were harvested by trypsinization, and each mouse was given injections of $1 \times 10^{6}$ cells subcutaneously into the right flank. Tumor growth was assessed every day by caliper measurement. Tumor volume $\left(\mathrm{mm}^{3}\right)$ was calculated by the formula: $\pi / 6 \times$ larger diameter $x$ (smaller diameter) ${ }^{2}$. In these experiments, all the mice were randomly divided into 4 groups and injected intraperitoneally (i.p.) with vehicle, Cet $(1 \mathrm{mg} / \mathrm{mice})$ alone, ORI $(20 \mathrm{mg} / \mathrm{kg})$ alone, or ORI and Cet in combination ( $\mathrm{n}=10$ per group). Animals in the control group were treated with DMSO and sterile PBS given by i.p. 
A

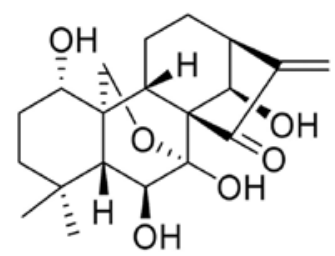

\section{B}

\section{HEp-2 cells}
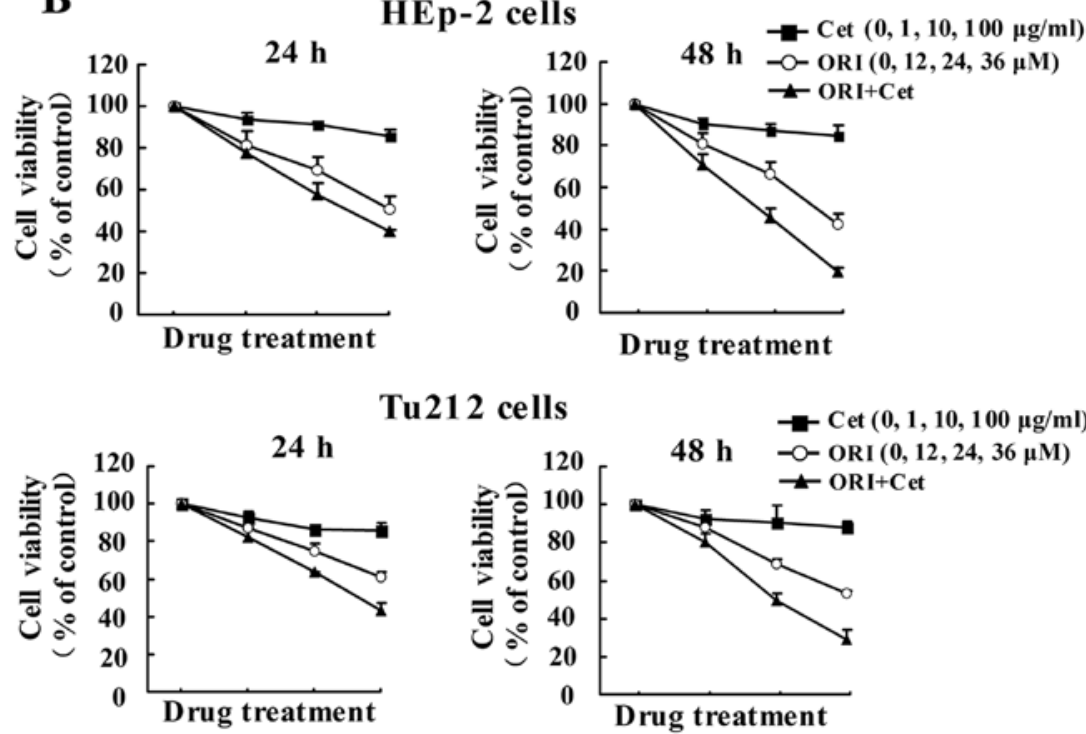

Tu212 cells

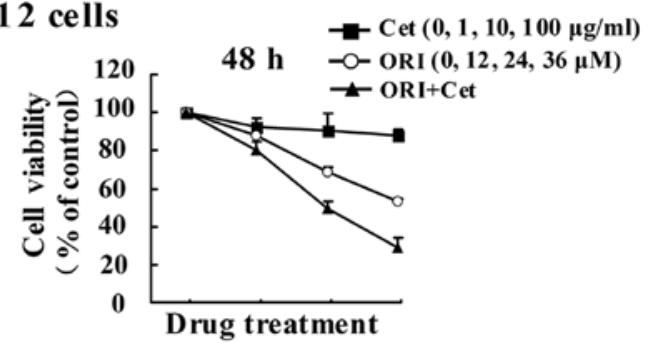

C
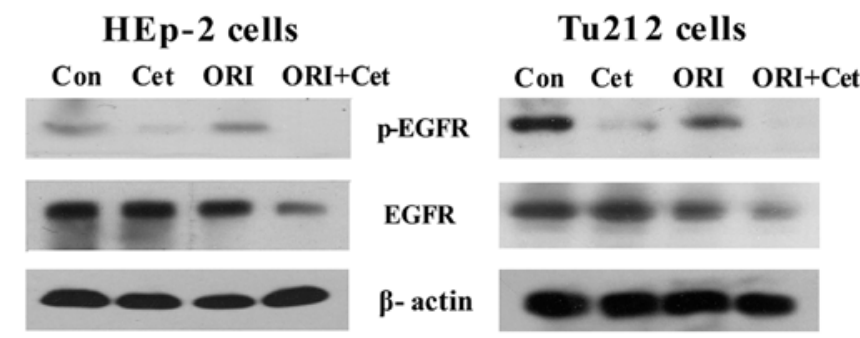

Figure 1. The effect of combined ORI and Cet on cell viability in LSCC cells. (A) The chemical structure of ORI. (B) MTT assay of LSCC cells in the presence of ORI and/or Cet. Cells were plated in 96 -well dishes and treated the next day with increasing doses of ORI $(0,12,24$ and $36 \mu \mathrm{M})$, Cet $(0,1,10$ and $100 \mu \mathrm{g} /$ $\mathrm{ml}$ ), or the combination for 24 and $48 \mathrm{~h}$. Results are expressed as percentage of cell number compared with the same cell line grown in the absence of the drugs. $\mathrm{n}=3$, Mean \pm SD. (C) The effect of combined ORI and Cet on the expression of p-EGFR and EGFR in the LSCC cells. LSCC cells were exposed to ORI ( $24 \mu \mathrm{M}$ for HEp-2 cells and $36 \mu \mathrm{M}$ for Tu212 cells, respectively) and Cet $(10 \mu \mathrm{g} / \mathrm{ml})$ for $48 \mathrm{~h}$, and the protein levels were determined by western blot analysis. $\beta$-actin was used as a loading control and blots are representative of at least 3 repeats.

In the study, all of the mice were sacrificed at the end of the treatment, and their tumors were harvested for immunohistochemical analysis. ELISA was used to test the ROS production of tumor sample, as previously described (25).

Immunohistochemistry and TUNEL assay. Immunohistochemical analysis of tumor tissue from nude mouse xenografts was performed following the standard protocol. Terminal deoxynucleotidyl transferase-mediated dUTP nick end labeling assay (TUNEL) was carried out according to the manufacturer's instructions (Promega, Madison, WI, USA) as previously described (26).

Western blot assays. Culture cells and subcutaneous tumors were lysed in cell lysis buffer, and the protein concentrations were determined using the Bradford absorbance assay. Protein expression was analyzed by western blot as previously described (22).
Data analysis. All data were analyzed using SPSS 17.0 software. One-way ANOVA was employed to analyze the differences between sets of data. For all analysis, $\mathrm{P}<0.05$ was considered to indicate a statistically significant result.

\section{Results}

Combined treatment with ORI and Cet induces LSCC cells death via inhibition of EGFR. The anti-proliferative effects of combination of ORI and Cet were examined using the MTT assay in LSCC cell lines. As shown in Fig. 1B, Cet alone only had a moderate inhibitory effect on the growth of LSCC cells, while ORI alone caused a time- and concentration-dependent inhibition of proliferation. Importantly, ORI in combination with Cet augmented growth inhibition of LSCC cells. The CI value of the combination of $24 \mu \mathrm{M}$ ORI and $10 \mu \mathrm{g} / \mathrm{ml} \mathrm{Cet}$ for $48 \mathrm{~h}$ was 0.59 for HEp- 2 cells, while the CI value of the combination of $36 \mu \mathrm{M}$ ORI and $10 \mu \mathrm{g} / \mathrm{ml}$ Cet for $48 \mathrm{~h}$ was 0.50 
A

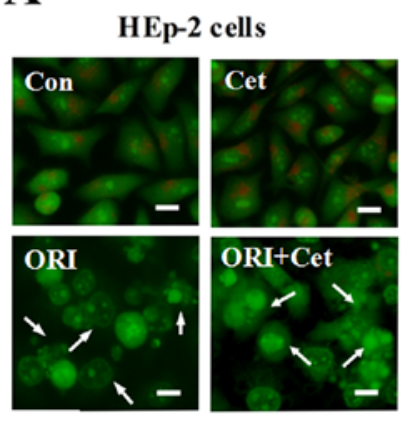

Tu212 cells

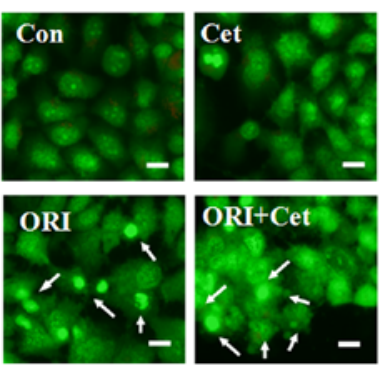

B

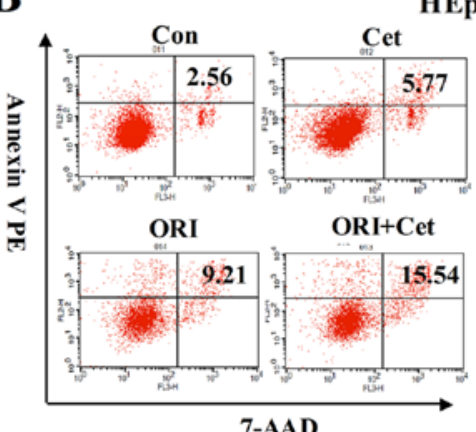

HEp-2 cells

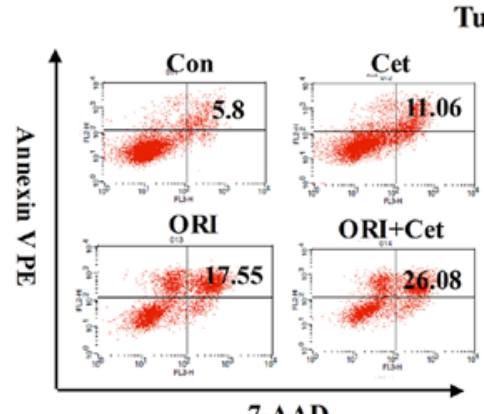

Tu212 cells

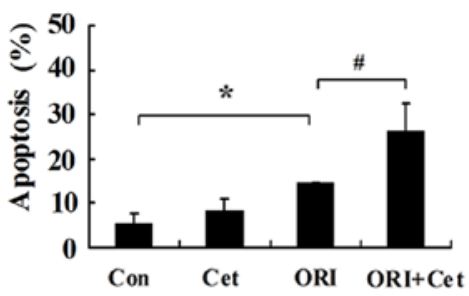

C

HEp-2 cells

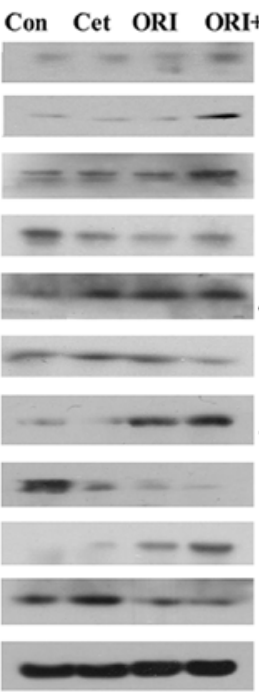

Fas

FADD

FasL

Caspase-8

Active caspase-8

Caspase-3

Active caspase-3

PARP

Cleaved PARP

ICAD

$\beta$-actin

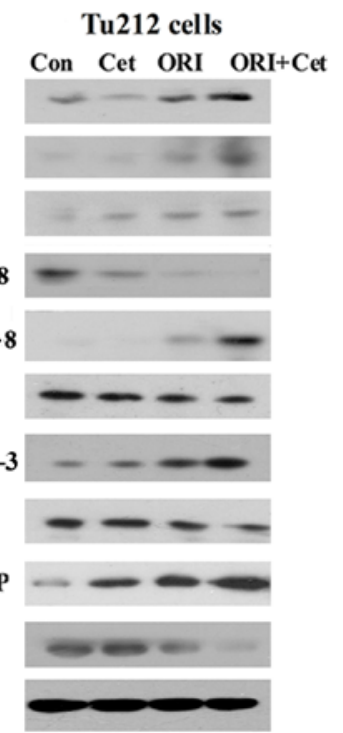

Figure 2. Combination of ORI and Cet synergistically induces Fas-dependent apoptosis in LSCC cells. (A) The cellular morphologic changes were observed under fluorescence microscopy with AO staining. Arrow indicates nuclear condensation and fragment. Bar represents $10 \mu \mathrm{m}$. (B) Induction of apoptosis was determined by staining with Annexin V-PE/7-AAD and flow cytometric analysis. Each histogram represents the mean \pm SD of three independent experiments. (C) The expressions of Fas, FasL, FADD, caspases, PARP and ICAD were determined by western blot analysis. $\beta$-actin was used as a standard to ensure equivalent loading of cell extracts. All blots are representative of at least 3 repeats. ${ }^{*} \mathrm{P}<0.05$ compared to the control group; ${ }^{\#} \mathrm{P}<0.05$ compared to the ORI alone group.

for Tu212 cells (Table I). The CI values $<1$ indicate that ORI and Cet exhibit synergistic growth inhibition of LSCC cells.

To characterize the expression of EGFR that might correlate with the observed growth inhibition, the effect of ORI/Cet combination on the levels of phosphorylated and total EGFR was examined by western blotting. Cet alone reduced p-EGFR expression in two LSCC cells, whereas ORI induced moderate inhibition. Combination treatment further decreased the expression of p-EGFR and total EGFR (Fig. 1C).

Combination of ORI and Cet induces apoptosis through activation of Fas-mediated extrinsic apoptotic pathway.
Next, we verified whether ORI and Cet exert an anticancer effect via induction of apoptosis. As shown in Fig. 2A, compared with the control group, more apoptotic cells were observed in ORI-treated and combination groups. ORI plus Cet caused strong apoptotic cell death in HEp-2 and Tu212 cells, which was higher than that caused by either agent alone (Fig. 2B).

Since the Fas/FasL system is an important apoptosis signal transduction pathway (27), we investigated whether the Fas/FasL-mediated pathway is related to the ORI/Cet combination-induced apoptosis. As shown in Fig. 2C, LSCC cells exposed to ORI alone increased the expression levels of 

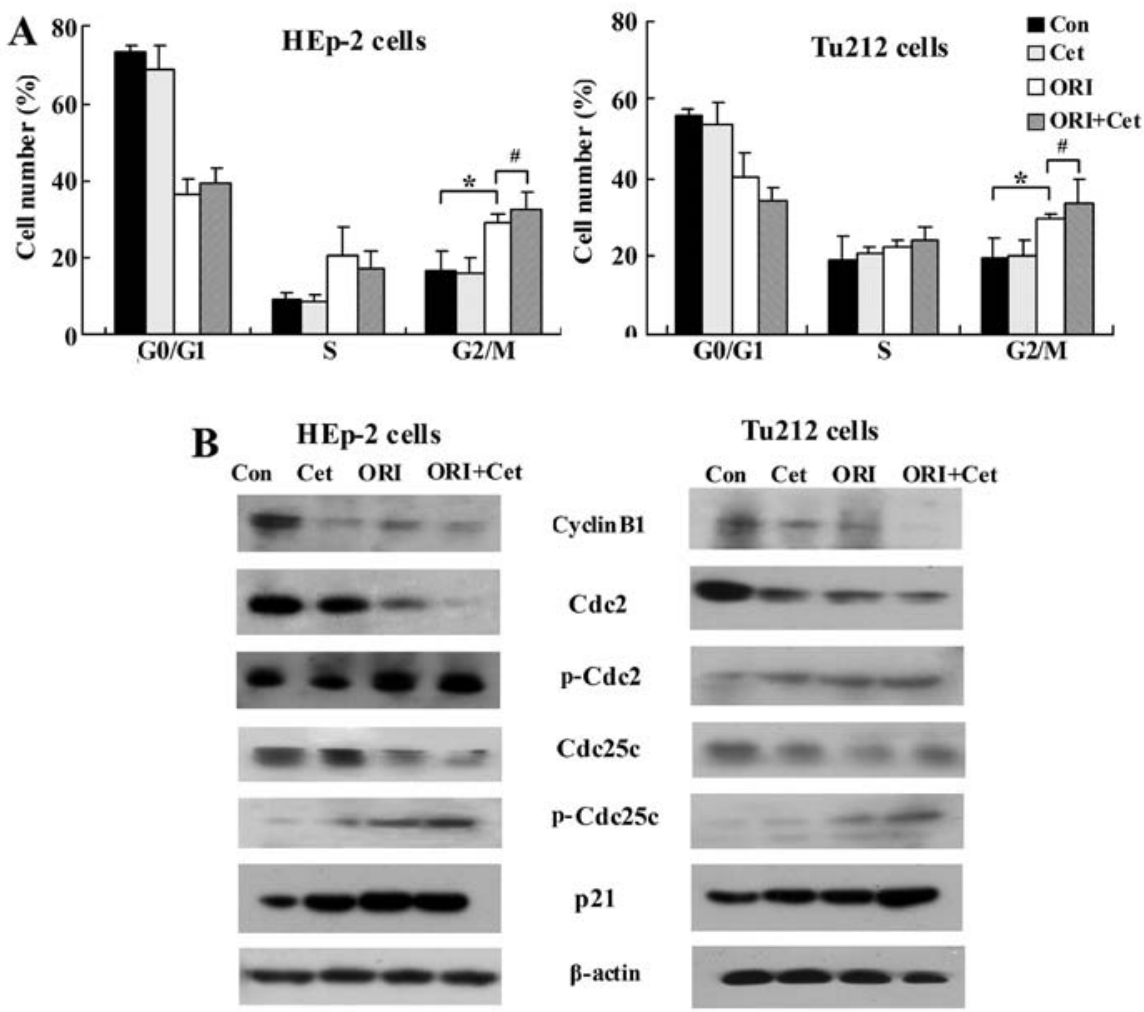

Figure 3. ORI/Cet induces G2/M phase cell cycle arrest and regulates the expression of cell cycle-regulating proteins. (A) Histogram of cycle distribution of HEp-2 and Tu212 cells after treatment with ORI ( $24 \mu \mathrm{M}$ for HEp-2 cells and $36 \mu \mathrm{M}$ for Tu212 cells, respectively) and Cet (10 $\mu \mathrm{g} / \mathrm{ml})$ for $48 \mathrm{~h}$. Cell cycle distribution was monitored by flow cytometry using propidium iodide (PI) staining assay. $n=3$, Mean \pm SD. (B) The protein levels of cell cycle-regulating proteins were detected by western blot analysis. Results presented are the mean from 3 parallel experiments. ${ }^{*} \mathrm{P}<0.05$, compared to the control group; ${ }^{\sharp} \mathrm{P}<0.05$, compared to the ORI alone group.

Table I. In vitro combination study of Cet with ORI in HEp-2 and Tu212 cells.

\begin{tabular}{|c|c|c|c|c|}
\hline \multirow{2}{*}{$\begin{array}{l}\text { Combining Cet } \\
\text { with ORI }\end{array}$} & \multicolumn{2}{|c|}{ CI of HEp-2 cells } & \multicolumn{2}{|c|}{ CI of Tu212 cells } \\
\hline & $24 \mathrm{~h}$ & $48 \mathrm{~h}$ & $24 \mathrm{~h}$ & $48 \mathrm{~h}$ \\
\hline \multicolumn{5}{|l|}{$1 \mu \mathrm{g} / \mathrm{ml} \mathrm{Cet}$} \\
\hline $12 \mu \mathrm{M}$ ORI & 0.75 & 0.71 & 1.51 & 0.66 \\
\hline $24 \mu \mathrm{M}$ ORI & 0.81 & 0.67 & 0.72 & 0.61 \\
\hline $36 \mu \mathrm{M}$ ORI & 0.66 & 0.63 & 0.55 & 0.51 \\
\hline \multicolumn{5}{|l|}{$10 \mu \mathrm{g} / \mathrm{ml}$ Cet } \\
\hline $12 \mu \mathrm{M}$ ORI & 0.78 & 0.73 & 1.23 & 0.78 \\
\hline $24 \mu \mathrm{M}$ ORI & 0.70 & 0.59 & 0.83 & 0.663 \\
\hline $36 \mu \mathrm{M}$ ORI & 0.60 & 0.62 & 0.50 & 0.50 \\
\hline \multicolumn{5}{|l|}{$100 \mu \mathrm{g} / \mathrm{ml} \mathrm{Cet}$} \\
\hline $12 \mu \mathrm{M}$ ORI & 0.99 & 1.02 & 1.89 & 0.68 \\
\hline $24 \mu \mathrm{M}$ ORI & 0.73 & 0.60 & 1.57 & 0.69 \\
\hline $36 \mu \mathrm{M}$ ORI & 0.56 & 0.64 & 0.67 & 0.54 \\
\hline
\end{tabular}

Combination index $(\mathrm{CI})<1$ indicates synergism; $\mathrm{CI}=1$ indicates additive effect; $\mathrm{CI}>1$ indicates antagonism.

Fas and FasL when compared to control cells. Importantly, the levels of Fas, FasL and FADD were significantly enhanced by
ORI plus Cet. Moreover, after 48-h exposure to ORI, we found that caspase-8, caspase-3 and PARP were cleaved to their active forms. Cleaved PARP, activated caspase- 3 and activated caspase- 8 were further increased as a result of the treatment with a combination of ORI and Cet. The expressions of ICAD were dramatically lower when both agents were combined compared with each agent alone.

Combined treatment with ORI and Cet induces G2/M phase cell cycle arrest. We further characterized the effects of ORI and Cet combination on the cell cycle distribution. As shown in Fig. 3A, Cet treatment did not show cell cycle arrest, whereas ORI caused G2/M arrest in LSCC cells compared to the control. Moreover, combination treatment with Cet and ORI resulted in a significant G2/M phase arrest compared with ORI given alone.

Next, the effects of ORI/Cet on the modulation of molecular events associated with the $\mathrm{G} 2 / \mathrm{M}$ phase were investigated in LSCC cells. As shown in Fig. 3B, ORI plus Cet resulted in a significant suppression of cyclin B1, which is essential for the transition from the S to the M-phase. Moreover, the combination of ORI and Cet decreased in Cdc25C and Cdc2 protein levels, but strongly increased the levels of p-Cdc2 and $\mathrm{p}-\mathrm{Cdc} 25 \mathrm{c}$ compared with either agent alone or control group. On the other hand, compared with each agent alone, ORI plus Cet moderately increased the protein levels of p21 (Fig. 3B), an upstream kinase associated with Cdc25Ccyclin B1/Cdc2 (28). 
A
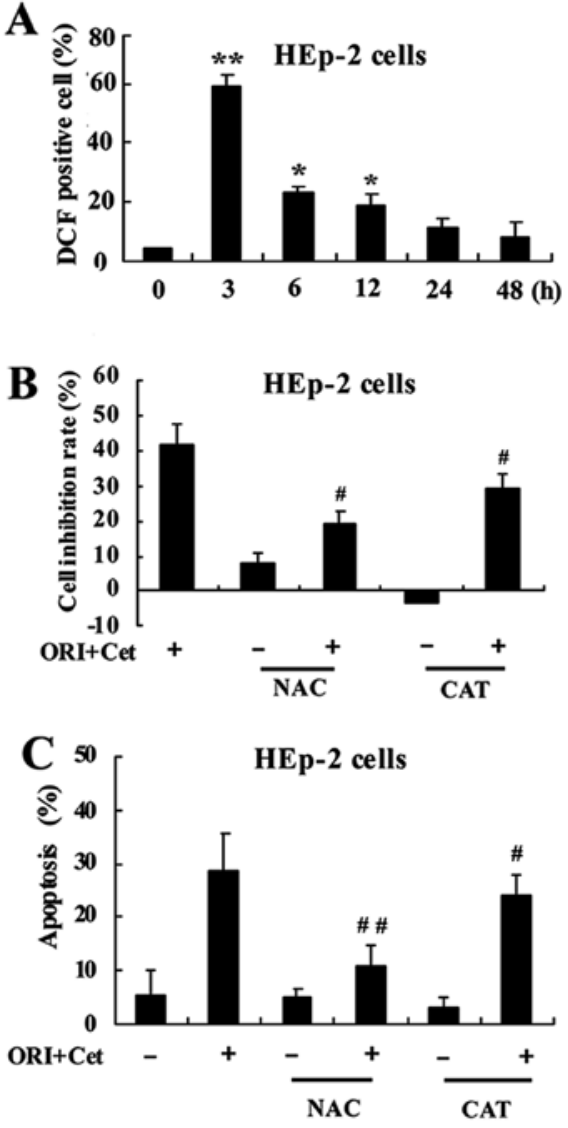

D
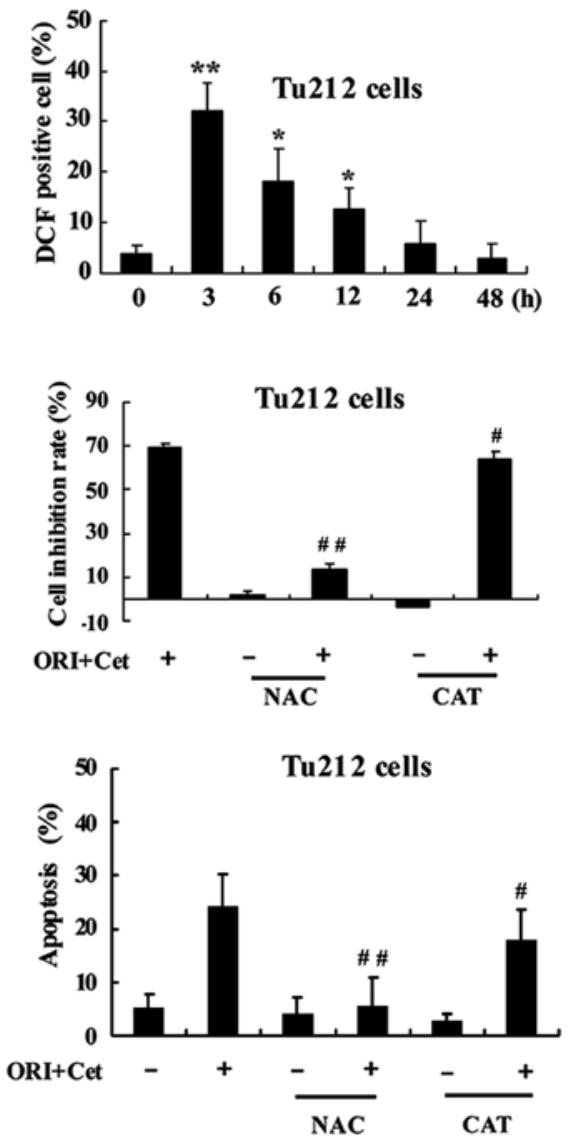

Tu212 cells

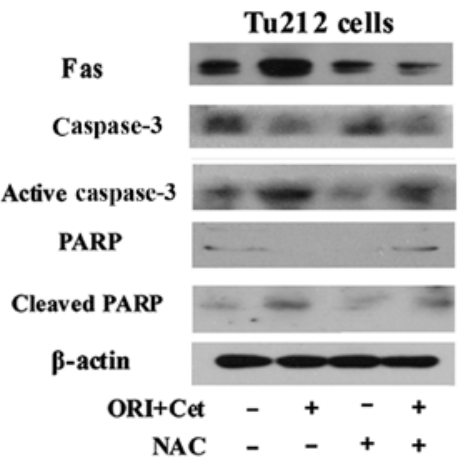

Figure 4. ORI/Cet stimulates the generation of ROS, which in turn mediates LSCC cell apoptosis. (A) HEp-2 and Tu212 cells were incubated with ORI ( $24 \mu \mathrm{M}$ for HEp-2 cells and $36 \mu \mathrm{M}$ for Tu212 cells, respectively) and Cet $(10 \mu \mathrm{g} / \mathrm{ml})$ for the indicated time periods. The generation of ROS was measured by using the fluorescent dye DCF-DA in flow cytometry. $\mathrm{n}=3$, Mean \pm SD. (B) The cells were pretreated with $2.5 \mathrm{mM} \mathrm{N}$-acetylcysteine (NAC) and $50 \mathrm{U} / \mathrm{ml}$ catalase $(\mathrm{CAT})$ for $1 \mathrm{~h}$ and then treated with ORI/Cet for $48 \mathrm{~h}$. Cell growth rate was measured by MTT assay. $\mathrm{n}=3$, Mean $\pm \mathrm{SD}$. (C) Apoptosis was detected through Annexin V-PE/7-AAD assay. $n=3$, Mean \pm SD. (D) The protein levels of Fas, PAPR and caspase-3 were detected by western blot analysis. " $P<0.05$, compared to the control group; ${ }^{\#} \mathrm{P}<0.05,{ }^{\# \#} \mathrm{P}<0.01$, compared to the combined treatment group.

ROS-mediated JNK pathway regulates ORI/Cet-induced apoptosis and cell cycle arrest. We investigated whether the cell growth inhibition induced by the combination of ORI and Cet was triggered by ROS accumulation. As shown in Fig. 4A, the treatment of LSCC cells with the combination of ORI and Cet could rapidly induce ROS production. The highest generation of ROS was observed after $3 \mathrm{~h}$ of exposure to the two agents.

To determine whether ROS is involved in cell growth inhibition induced by the combination of ORI and Cet, NAC (N-acetylcysteine) and CAT (catalase), two general free radical scavengers $(29,30)$, were introduced. NAC and CAT showed significant inhibitory effects on ORI/Cet-induced cell growth inhibition (Fig. 4B). Moreover, the percentage of apoptotic cells of combination groups were significantly reduced after pretreatment with NAC and CAT (Fig. 4C). NAC could partly inhibit the expression of the cleaved PARP and activated caspase-3 induced by ORI/Cet (Fig. 4D). On the other hand, the proportion of LSCC cells treated with ORI/Cet plus NAC or CAT in G2/M phase was significantly lower than that in cells treated with ORI/Cet (Fig. 5). Pretreatment with NAC showed a significant protection against ORI/Cet-induced Cdc2 and cyclin B1 degradation (Fig. 5).

Next, we explored the contribution of MAPK (mitogenactivated protein kinase) family proteins ERK, JNK and p38 to the ORI/Cet-induced cell apoptosis and G2/M phase 

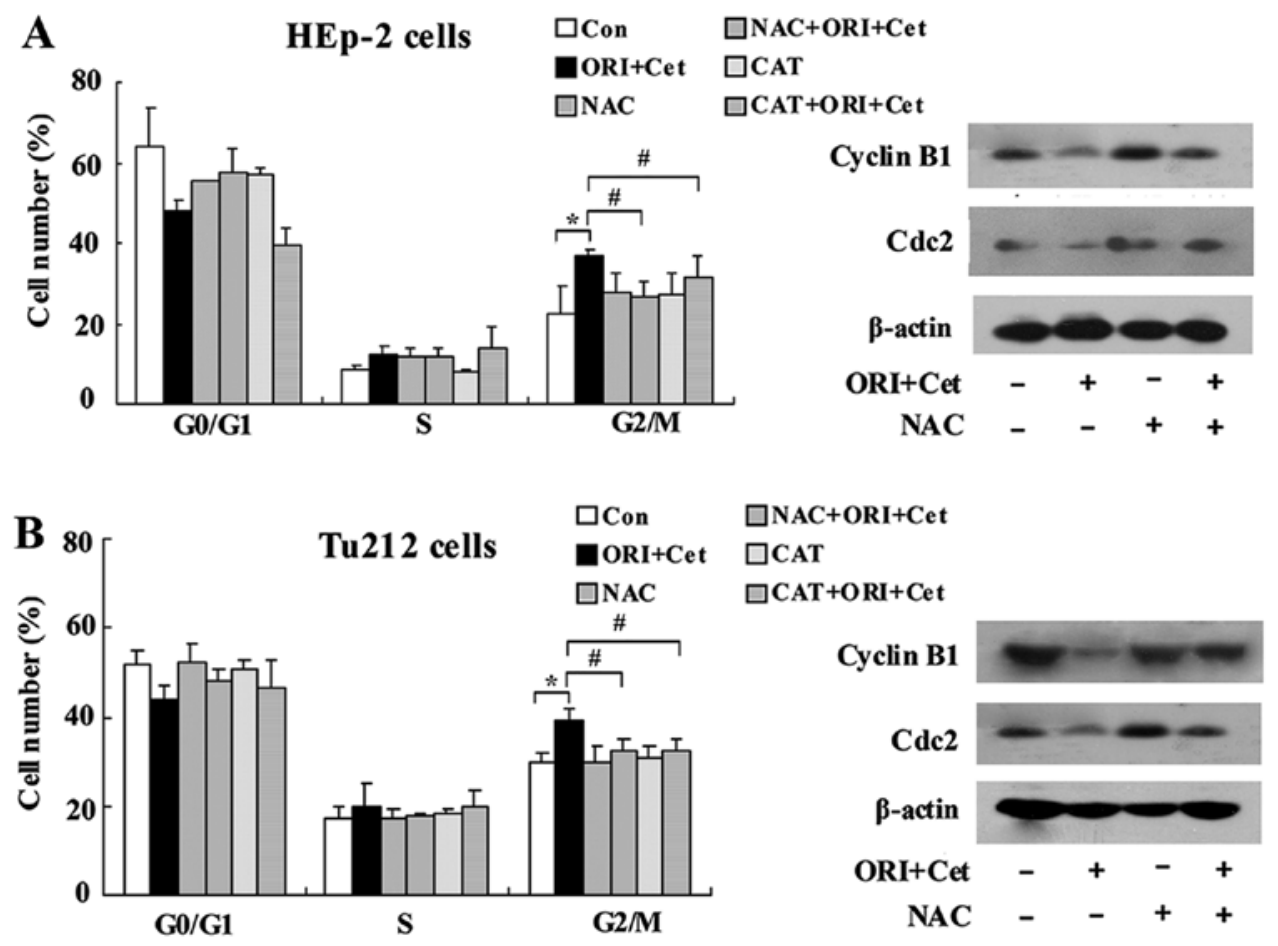

Figure 5. Combination of ORI and Cet induces G2/M arrest via ROS. (A) LSCC cells were pretreated with either NAC or CAT for $1 \mathrm{~h}$, followed by treatment with ORI plus Cet for $48 \mathrm{~h}$. The cells were then stained with PI, followed by flow cytometric analysis. (B) The expression of cyclin B1 and Cdc2 were determined by western blot analysis. $\beta$-actin worked as the loading control. All blots are representative of at least 3 repeats. " $\mathrm{P}<0.05$, compared to the control group; ${ }^{*} \mathrm{P}<0.05$, compared to the combined treatment group.

arrest. As shown in Fig. 6A, pretreatment with JNK inhibitor SP600125 (31) exhibited a significant inhibitory effect on cytotoxicity of the combination of ORI and Cet in LSCC cells, while pretreatment with ERK inhibitor PD98059 and p38 inhibitor SB203580 markedly increased ORI/Cet-induced cytotoxicity. Moreover, both ORI and Cet upregulated the level of p-JNK in the LSCC cells. Treatment of cells with ORI combined with Cet strongly increased the expression of p-JNK (Fig. 6B). In addition, compared with the combination group, inhibiting JNK resulted in decreased apoptosis in ORI/Cet-treated LSCC cells (Fig. 6C). The levels of Fas, cleaved PARP and activated caspase-3 were decreased by SP600125 (Fig. 6D). On the other hand, the inhibition of JNK was associated with obvious abolition of ORI/Cet-induced G2/M arrest (Fig. 7A). Addition of SP600125 abolished ORI/Cet-induced downregulation of cyclin B1 and Cdc2 (Fig. 7B). Notably, western blot results indicated that inhibiting the generation of ROS partly inhibited the ORI/Cet-induced upregulation of p-JNK both in HEp-2 cells and Tu212 cells (Fig. 7C). All these results suggested that ROS-mediated JNK pathway participated in the regulation of $\mathrm{G} 2 / \mathrm{M}$ phase arrest and apoptosis induced by ORI/Cet treatment.

Combined treatment of ORI with Cet leads to in vivo tumor regression through inhibiting the activation of EGFR. To characterize the in vivo effects of the combination of ORI and Cet, a series of experiments were conducted in HEp-2 tumor xenografts. As shown in Fig. 8A, ORI and Cet alone produced significant growth inhibition in HEp-2 xenografts. Combined treatment of Cet with ORI further inhibited tumor growth and resulted in substantial growth delay in the HEp-2 xenografts.
All of the treatments were well tolerated, and there were no signs of toxicity or body weight loss during therapy.

We also elucidated the molecular mechanisms of the treatment effects with ORI plus Cet on mouse HEp-2 xenografts. Cet alone had a minimum effect on p-EGFR expression, whereas ORI alone effectively reduced p-EGFR expression levels. The levels of p-EGFR in the combined treatment group were significantly lower than that in the ORI group (Fig. 8B and D).

We further evaluated tumor cell proliferation by PCNA staining. Treatment with ORI or Cet alone decreased the percentage of PCNA-positive proliferating tumor cells, with proliferation indices of 40 and $47 \%$, respectively. Combined treatment with ORI and Cet markedly decreased the percentage of PCNA-positive proliferating tumor cells to $9 \%$ (Fig. 8B and C). We also examined whether treatment with ORI and/or Cet induced apoptosis in vivo in HEp-2 tumors. Combined treatment significantly increased the percentage of apoptotic cells to $46.3 \%$ compared with the cells of monotreated (ORI 29.3 and Cet 13\%) or control mice (3\%) (Fig. 8B and $\mathrm{C}$ ). In addition, ORI plus Cet increased the activation of caspase- 8 and caspase-3 (Fig. 8D).

Next, we detected the expression of cyclin B1 in the tumor tissue. As shown in Fig. 8B and D, Cet and ORI treatments decreased the percentage of mitotic cells as indicated by a decrease in the number of cyclin B1 positive cells. Similar to in vitro findings, there were fewer cells positive for cyclin B1 in the combination group than in ORI-treated group.

Combining ORI and Cet induces ROS production and JNK activation in HEp-2 xenografts. To investigate whether ORI 


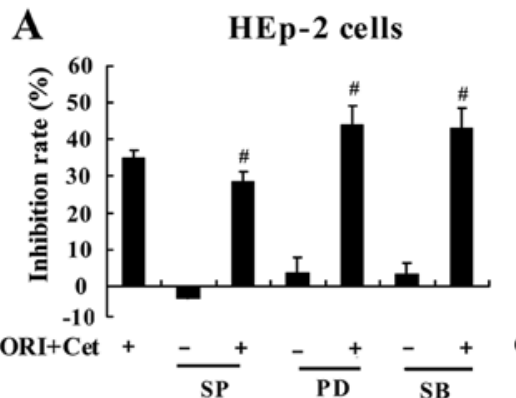

Tu212 cells

B
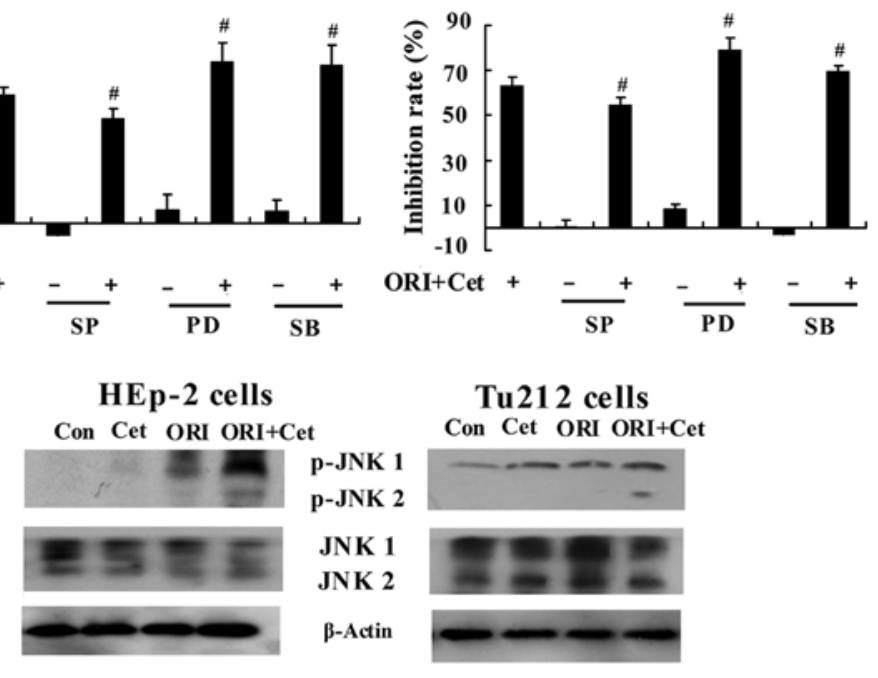

Tu212 cells Con Cet ORI ORI+Cet
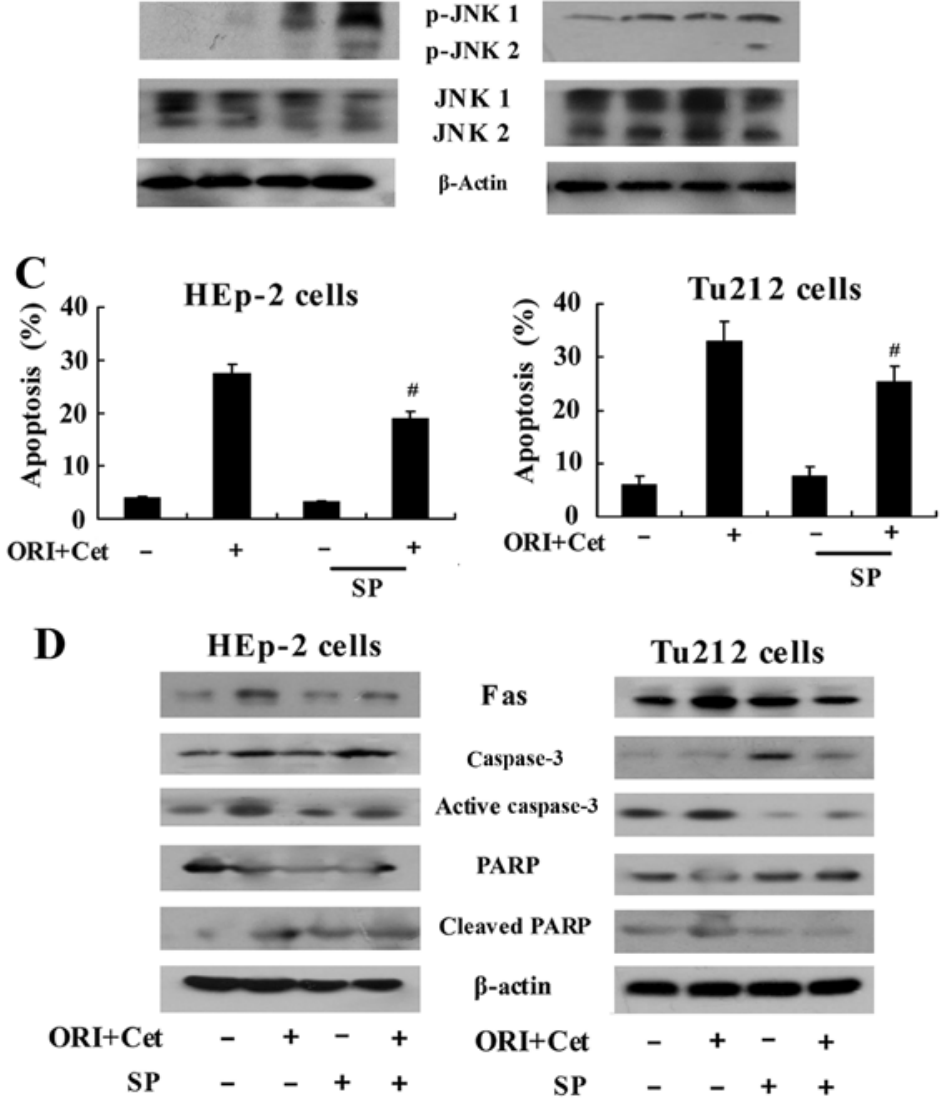

Figure 6. Combination of ORI and Cet induces apoptosis through activating JNK. (A) HEp-2 and Tu212 cells were pretreated with JNK inhibitor SP600125 (SP), p38 inhibitor SB203580 (SB) and ERK inhibitor PD98059 (PD) for $1 \mathrm{~h}$ and then treated with ORI ( $24 \mu \mathrm{M}$ for HEp-2 cells and $36 \mu \mathrm{M}$ for Tu212 cells, respectively) and Cet $(10 \mu \mathrm{g} / \mathrm{ml})$ for $48 \mathrm{~h}$. Cell growth rate was measured by MTT assay. $\mathrm{n}=3$, Mean \pm SD. (B) HEp- 2 and Tu212 cells were incubated with ORI and Cet for $48 \mathrm{~h}$. The expression of JNK and p-JNK were determined by western blot analysis. (C and D) LSCC cells were pre-incubated with or without SP for $1 \mathrm{~h}$, then treated with the combination of ORI and Cet for $48 \mathrm{~h}$ and analyzed by flow cytometry and western blotting to evaluate apoptosis and related proteins. ${ }^{\#} \mathrm{P}<0.05$, compared to the combined treatment group.

plus Cet induced ROS generation in vivo, the levels of ROS in the different treatment tumor tissues were examined. As shown in Fig. 8E, compared with the control group, both ORI and combination treatment resulted in a more significant elevation in ROS levels. However, no statistical difference in ROS levels was observed between the ORI and combined treatment group.

To substantiate the activation of JNK induced by the combination of ORI and Cet in vivo, p-JNK in xenograft tissues was revealed by immunohistochemistry and western blotting. As shown in Fig. 8B and D, p-JNK was detected in ORI and Cet-treated xenograft tissues compared with the control group, and combined treatment with ORI and Cet significantly increased the expression levels of p-JNK in tumors.

\section{Discussion}

In comparison with normal tissues, LSCC shows higher expression of EGFR, which promotes processes responsible for tumor growth and progression (6). Cet, an anti-EGFR monoclonal antibody, has failed to bring the expected antitumor outcome (14). Additionally, Cet is not sufficient to induce apoptosis and generally has less cytostatic effects on cell growth in many tumor cell lines $(32,33)$, including LSCC cells. However, in combination with several anticancer agents from natural products, Cet has been shown to increase the incidence of human tumor cell apoptosis in a number of model systems. Park et al (34) observed marked antitumor activity with the 

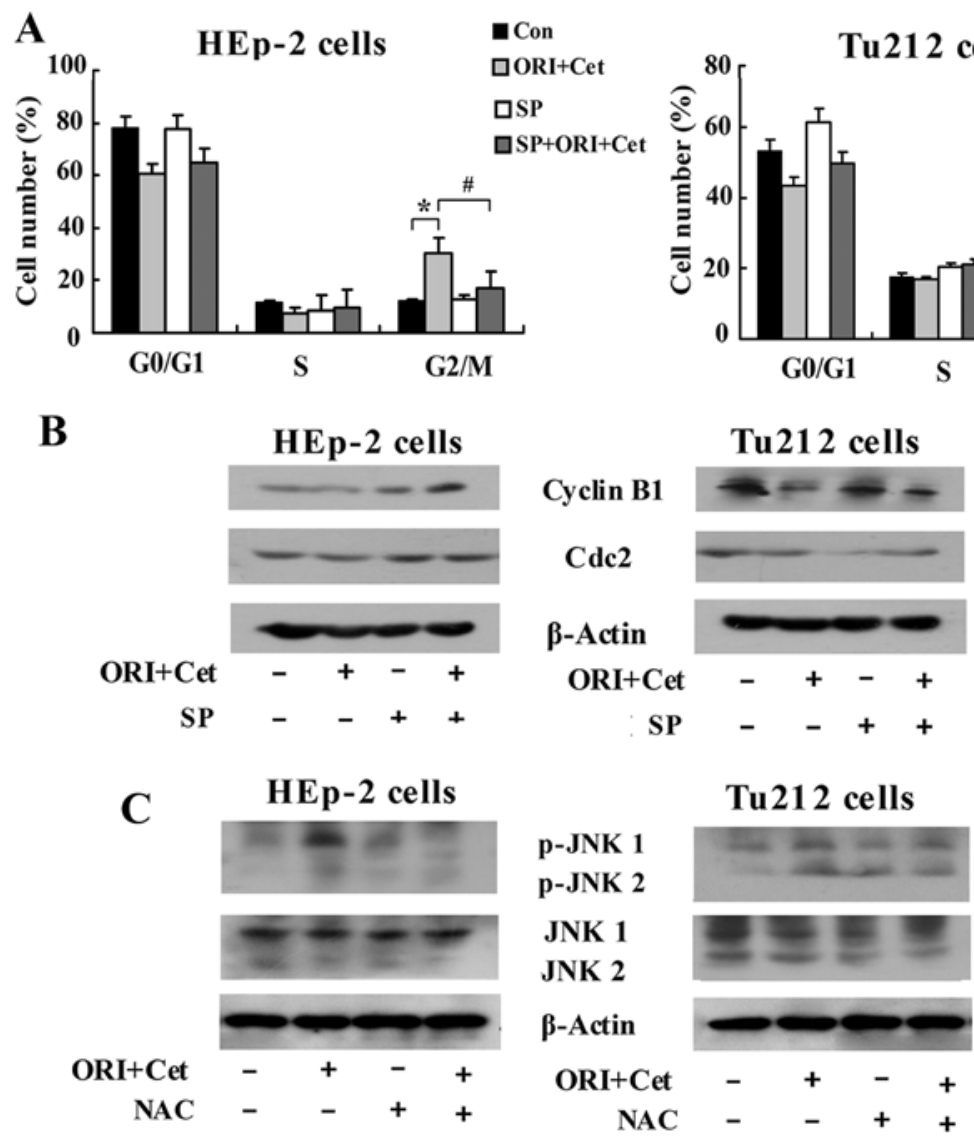

Figure 7. ORI/Cet induces G2/M phase arrest through ROS-mediated JNK pathway. (A and B) Flow cytometry and western blotting to evaluate cell cycle and related proteins. (C) LSCC cells were pre-incubated with or without NAC for $1 \mathrm{~h}$, then treated with the combination of ORI and Cet for $48 \mathrm{~h}$ and analyzed the protein levels of JNK and p-JNK. $\beta$-actin worked as the loading control. All blots are representative of at least 3 repeats. "P<0.05, compared to the control group; ${ }^{\prime} \mathrm{P}<0.05$, compared to the combined treatment group.

combination of Cet and genistein, a natural isoflavonoid derived from soy, in mice bearing an oral squamous cell carcinoma (OSCC) xenograft. Cet in combination with docetaxel, a taxoid derived from the needles of the European yellow tree, could inhibit the proliferation of non-small cell lung cancer PC9/G2 cells in vitro and in vivo (35). Leeman-Neill et al (36) reported that guggulsterone, a naturally-occurring compound used in traditional Indian medicine, augments Cet-induced cell growth inhibition of HNSCC. Consistent with these observations, our results firstly demonstrated that a combination of Cet and ORI, an active component from Rabdosia rubescens, is an effective way to achieve synergistic antitumor effects against LSCC in vitro and in vivo. The present study also explored the potential mechanisms underlying the observed synergy of the combined treatment.

ORI was reported to exhibit potent antitumor effects against many cell lines through different mechanisms including MAPK, mTOR and NF- $\kappa \mathrm{B}(37,38)$. In addition, ORI led to apoptosis in A431 cells (39), H1975 cells (40) and HEp-2 cells (22) through blockage of EGFR phosphorylation. Herein, our results also demonstrated that ORI could inhibit EGFR phosphorylation both in vitro and in vivo. Cet alone showed stronger suppression on EGFR phosphorylation than ORI alone in vitro, whereas ORI had stronger antiproliferation effect on LSCC cells compared to Cet alone, suggesting that except EGFR pathway, the growth inhibitory effect of ORI appears to be associated with other signaling pathways. Importantly, combination of ORI with Cet has synergistic anti-proliferative activity in vitro with significant inhibition of p-EGFR expression. In addition, we observed that the combination treatment with ORI and Cet significantly suppressed levels of p-EGFR in tumor tissue and caused tumor regression of HEp-2 xenograft in vivo, compared with ORI or Cet alone. We did not observe any serious side-effects in the treatment groups during the entire experimental period. These results suggest that the two agents given together had a potent anticancer effect against LSCC through downregulation of p-EGFR.

Decreased activity of EGFR leads to downregulation of several downstream signaling cascades resulting in apoptosis of cancer cells (41). Consistent with this report, our results demonstrated that the inhibitory effects of the combined treatment with ORI and Cet on the EGFR phosphorylation was accompanied by a marked apoptosis in vitro and in vivo. It was reported that anti-EGFR inhibitors decreased phosphorylation of EGFR and its downstream effector Akt and amplified the induction of Fas-mediated apoptosis (42). Here, LSCC cells when co-treated with ORI and Cet showed higher expressions of Fas, FasL and activated caspase- 8 than those in ORI alonetreated cells. Furthermore, in the HEp-2 tumor xenografts, combined treatment resulted in significant apoptosis as well as marked increase in activated caspase- 8 and -3 , suggesting 
A
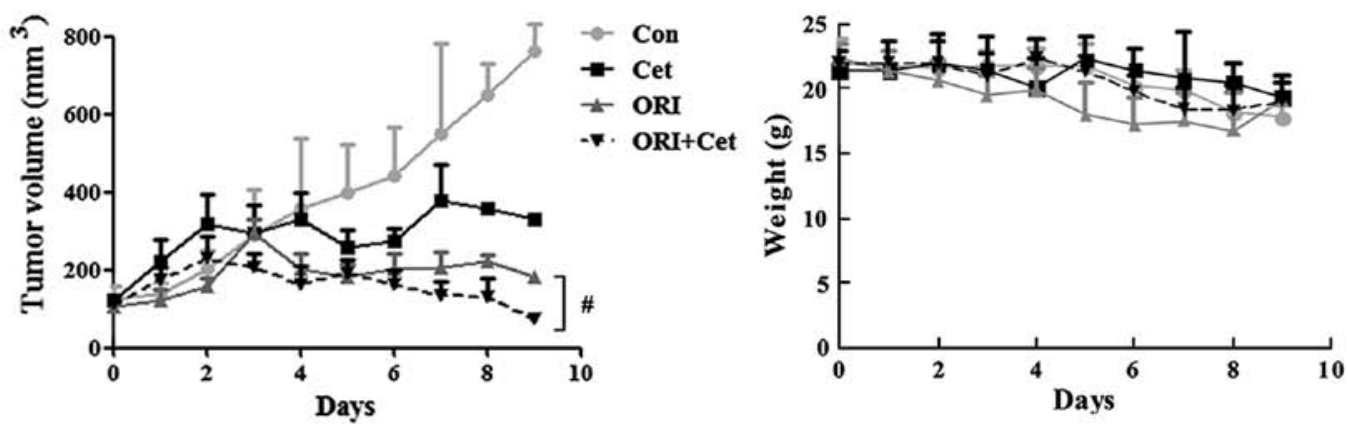

B

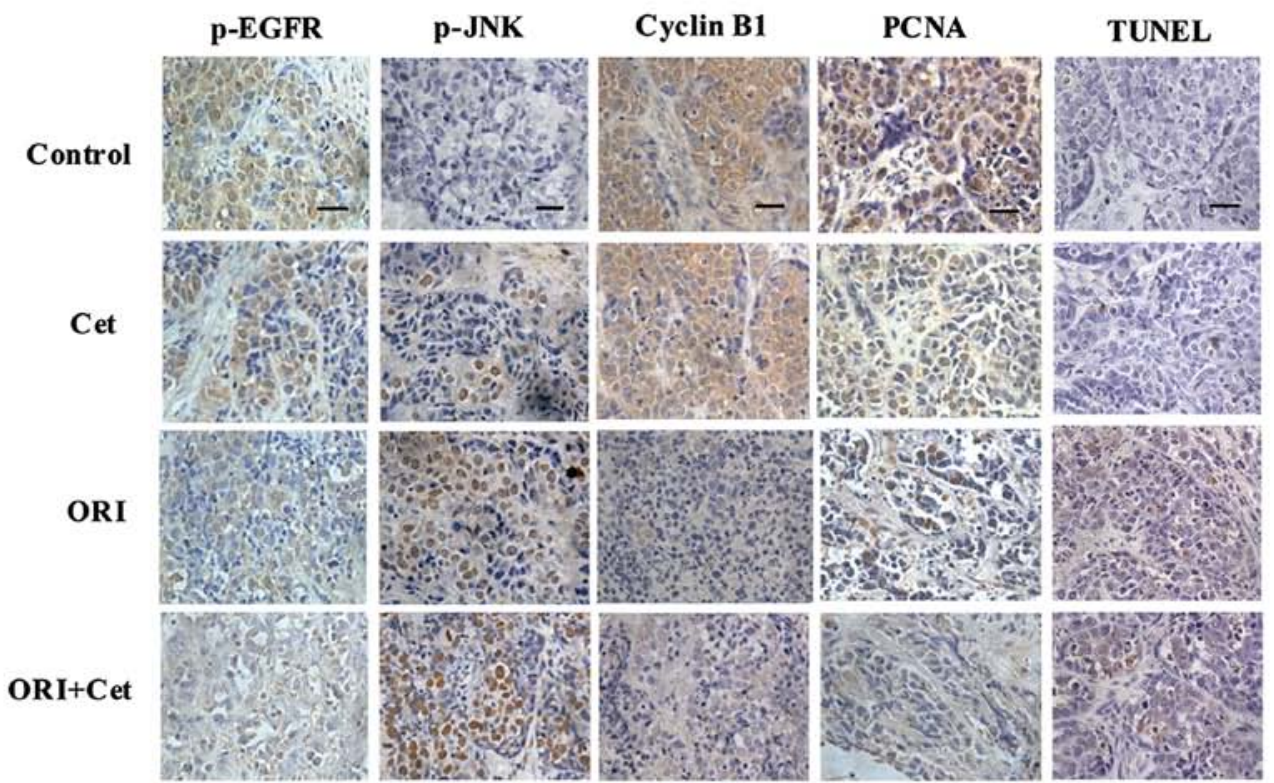

C
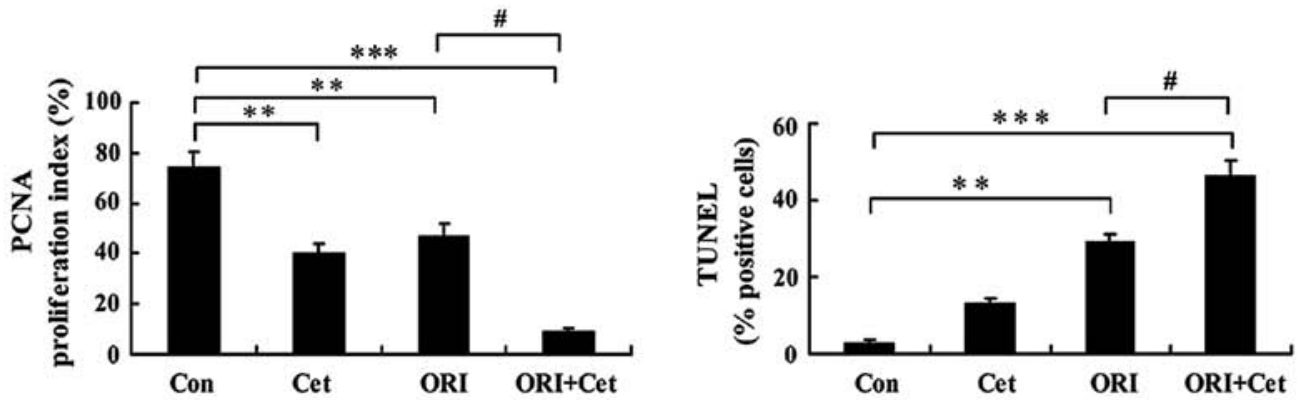

D
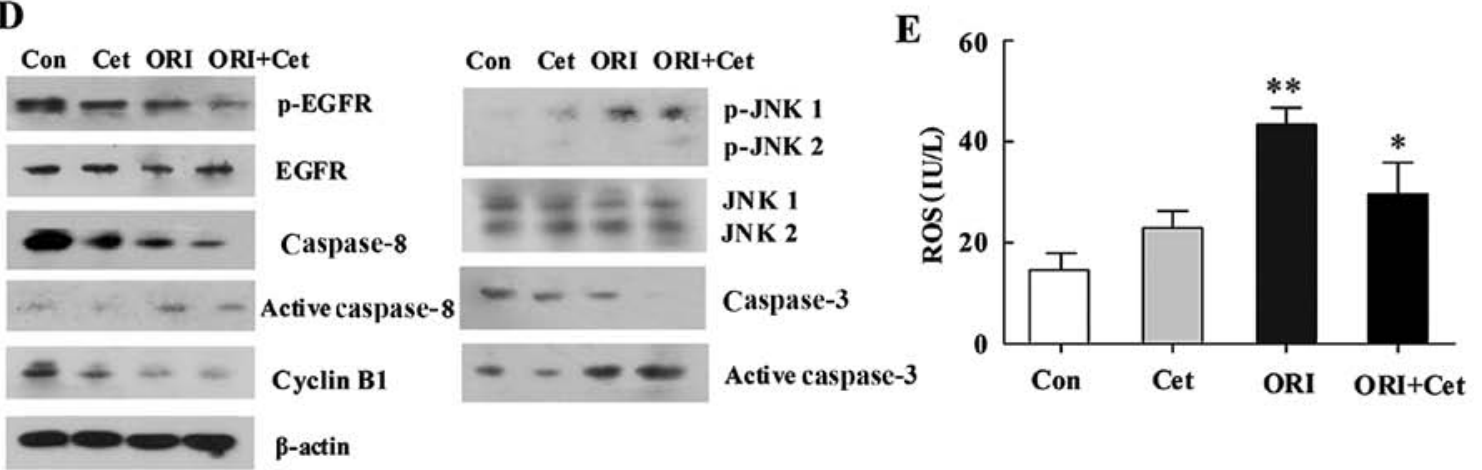

Figure 8. ORI/Cet significantly inhibits HEp-2 growth and induces apoptosis in a xenograft mouse model. (A) Mice bearing HEp-2 xenografts were treated with vehicle, ORI ( $20 \mathrm{mg} / \mathrm{kg} / \mathrm{day})$, Cet (1 mg/kg twice for 5 days) or their combination for 10 days. Each group included 10 mice. Tumor volume was measured every day. After 10 days, the mice were sacrificed and the tumors were removed and analyzed. Data are expressed as mean ( \pm SEM) tumor volume. Body weight of mice with HEp-2 xenografts was measured every day during treatment with vehicle control, ORI, Cet or their combination. (B) Representative images of HEp-2 tumors immunohistochemically stained with antibodies to p-EGFR, p-JNK, cyclin B1 and PCNA, and representative images of apoptotic cell death in HEp-2 tumors as measured by the TUNEL assay. Bar represents $10 \mu \mathrm{m}$. (C) Quantification of proliferation index (PCNA) and apoptosis index (TUNEL). (D) Expression levels of p-EGFR, EGFR, p-JNK, JNK, cyclin B1 and caspases in tumor tissues from various treatment groups were analyzed by western blot analysis. (E) ELISA measurement of the ROS level in tumors tissues treated by ORI and/or Cet. $\mathrm{n}=4$, Mean \pm SD. ${ }^{*} \mathrm{P}<0.05,{ }^{* * *} \mathrm{P}<0.01,{ }^{* * * *} \mathrm{P}<0.001$ compared to the control group; ${ }^{~} \mathrm{P}<0.05$ compared to the ORI alone group. 
that Fas-mediated extrinsic pathway plays an important role in ORI/Cet-induced tumor cell death.

Previous studies have demonstrated that Cet inhibits cell cycle progression in non-small cell lung cancer lines, causing cells to arrest in the G1 gap phase that occurs prior to DNA synthesis (43). Nevertheless, Cet did not induce G0/G1 phase arrest in our models, which might be attributed to our use of different cell lines or the dose of Cet. The present results were in agreement with previous reports that ORI could induce G2/M arrest in HEp-2 (44), HCT116 (45) and MCF-7 cells (46). Interestingly, Cet strongly enhanced ORI-caused G2/M arrest in vitro and in vivo. It is now established that p21 is a universal inhibitor of cyclin kinases which controls cell cycle by activating and/or inactivating the cyclin-dependent kinases (28). Cdc25C is a critical regulator of $\mathrm{Cdc} 2 /$ cyclin $\mathrm{B} 1$ kinase activity and controls cell cycle progression by dephosphorylating and activating CDKs (47). In the present study, the combined treatment of Cet and ORI moderately increased p21 levels, which phosphorylated and inactivated $\mathrm{Cdc} 25 \mathrm{c}$, resulting in the inactivation of cyclin B1/Cdc 2 complex. Hence, our findings support that $\mathrm{p} 21-\mathrm{Cdc} 25 \mathrm{C}$-cyclin $\mathrm{B} 1 / \mathrm{Cdc} 2$ pathway could be one of the possible underlying molecular events associated with the strong synergistic effect of the ORI/Cet combination on $\mathrm{G} 2 / \mathrm{M}$ arrest in LSCC cells.

ROS act as secondary messengers and are essential for cell signaling and various cellular processes, including apoptosis and cell cycle arrest (48). It is reported that ORI induced apoptosis and G2/M arrest via ROS activation in L929 cells (49) and HEp-2 cells (44). The present study demonstrated that ORI induced apoptosis and G2/M arrest via ROS generation not only in HEp-2 cells but also in Tu212 cells, another type of LSCC cell line. In addition, the combination group also induced significant ROS production both in vitro and in vivo. However, combined treatment did not induce more ROS generation compared with the ORI alone group in vivo, indicating that other mediators might be involved in the antitumor effect of combination treatment with ORI and Cet in vivo. Furthermore, NAC or CAT pretreatment resulted in the marked inhibition of ORI/Cet-induced cell growth inhibition, apoptosis and Fas expression, indicating that combination treatment induced Fas-dependent apoptosis through ROS generation in LSCC cells. Moreover, pretreatment with NAC or CAT significantly decreased ORI/Cet-induced G2/M arrest, suggesting that combination of ORI and Cet caused ROS generation which is involved with combined treatment induced $\mathrm{G} 2 / \mathrm{M}$ arrest. Taken together, these results suggest that the combined treatment with ORI and Cet could trigger ROS generation, which was related to the Fas-dependent apoptosis and G2/M phase arrest in LSCC cells.

MAPK cascades are activated by various cellular stresses and growth factors, which are signaling transduction molecules in apoptosis and cell cycle arrest (50). JNK pathway, as an important subgroup of MAPK super family, has been reported to be involved in tumor cell death induced by different chemotherapeutic agents (51). Herein, we demonstrated that combination of ORI and Cet remarkably increased the levels of p-JNK in vitro and in vivo. Additionally, the inhibition of JNK by SP600125 decreased, in part, the ORI/Cet-induced cell death, apoptosis, G2/M arrest and related protein, suggesting that JNK activation contributed to
ORI/Cet-induced extrinsic apoptosis and G2/M arrest. The involvement of JNK in ORI/Cet-induced growth inhibition is partial, and additional studies are still necessary to identify the other actors involved in this mechanism including the downstream effectors of EGFR, such as STAT or Akt. In addition, although diverse stimuli activate MAPK pathways, in many cases, the generation of ROS is responsible for increases in MAPK activity (52). In the present study, we found that NAC significantly inhibited the phosphorylation of JNK in LSCC cells especially in HEp-2 cells, suggesting that ORI/Cet-induced JNK activation was mediated through ROS generation. Together, these findings imply that ROS might be an upstream mediator of JNK activation, which initiates the series of apoptotic events and G2/M phase arrest induced by ORI/Cet.

In summary, the present study shows that combined treatment of ORI and Cet exerts synergistic effects on cell growth inhibition via downregulation of p-EGFR. ORI plus Cet activates ROS mediated-JNK pathway, and invokes strong anticancer activity against LSCC by inducing apoptosis and $\mathrm{G} 2 / \mathrm{M}$ cell arrest in vivo and in vitro. Thus, a combination of ORI and Cet might be a promising approach for the treatment of laryngeal cancer.

\section{Acknowledgements}

The present study was supported by the National Natural Science Foundation of China (no. 81373797), the China Postdoctoral Science Special Foundation (no. 2014T70224) and the China Postdoctoral Science Foundation (no. 2013M541192).

\section{References}

1. Parkin DM, Bray F, Ferlay J and Pisani P: Global cancer statistics, 2002. CA Cancer J Clin 55: 74-108, 2005.

2. Siegel R, Naishadham D and Jemal A: Cancer statistics, 2013. CA Cancer J Clin 63: 11-30, 2013.

3. Forastiere A, Koch W, Trotti A and Sidransky D: Head and neck cancer. N Engl J Med 345: 1890-1900, 2001.

4. Jorissen RN, Walker F, Pouliot N, Garrett TP, Ward CW and Burgess AW: Epidermal growth factor receptor: Mechanisms of activation and signalling. Exp Cell Res 284: 31-53, 2003.

5. Rocha-Lima CM, Soares HP, Raez LE and Singal R: EGFR targeting of solid tumors. Cancer Control 14: 295-304, 2007.

6. Itakura Y, Sasano H, Shiga C, Furukawa Y, Shiga K, Mori S and Nagura H: Epidermal growth factor receptor overexpression in esophageal carcinoma. An immunohistochemical study correlated with clinicopathologic findings and DNA amplification. Cancer 74: 795-804, 1994.

7. Li FC, Li YH, Zhao X, Fu WN, Xu ZM, Li ZG and Sun KL: Association of homozygous deletion of p15 and p16 gene and amplification of EGFR gene in laryngeal squamous cell carcinoma. Yi Chuan Xue Bao 31: 109-113, 2004 (In Chinese).

8. Li F, Kang N, Fu W, Sun X, Gao H and Sun K: Detection of epidermal growth factor receptor gene amplification in human laryngeal carcinomas by means of fluorescence in situ hybridization. Zhonghua Yi Xue Yi Chuan Xue Za Zhi 17: 278-280, 2000 (In Chinese).

9. Moghal N and Sternberg PW: Multiple positive and negative regulators of signaling by the EGF-receptor. Curr Opin Cell Biol 11: 190-196, 1999.

10. Prewett M, Rockwell P, Rockwell RF, Giorgio NA, Mendelsohn J, Scher HI and Goldstein NI: The biologic effects of C225, a chimeric monoclonal antibody to the EGFR, on human prostate carcinoma. J Immunother Emphasis Tumor Immunol 19: 419-427, 1996 
11. Matar P, Rojo F, Cassia R, Moreno-Bueno G, Di Cosimo S, Tabernero J, Guzmán M, Rodriguez S, Arribas J, Palacios J, et al: Combined epidermal growth factor receptor targeting with the tyrosine kinase inhibitor gefitinib (ZD1839) and the monoclonal antibody cetuximab (IMC-C225): Superiority over single-agent receptor targeting. Clin Cancer Res 10: 6487-6501, 2004.

12. Huether A, Höpfner M, Baradari V, Schuppan D and Scherübl H: EGFR blockade by cetuximab alone or as combination therapy for growth control of hepatocellular cancer. Biochem Pharmacol 70: $1568-1578,2005$.

13. Galizia G, Lieto E, De Vita F, Orditura M, Castellano P, Troiani T, Imperatore V and Ciardiello F: Cetuximab, a chimeric human mouse anti-epidermal growth factor receptor monoclonal antibody, in the treatment of human colorectal cancer. Oncogene 26: 3654-3660, 2007.

14. Kohrt HE, Colevas AD, Houot R, Weiskopf K, Goldstein MJ, Lund P, Mueller A, Sagiv-Barfi I, Marabelle A, Lira R, et al: Targeting CD137 enhances the efficacy of cetuximab. J Clin Invest 124: 2668-2682, 2014

15. Le Tourneau C and Siu LL: Molecular-targeted therapies in the treatment of squamous cell carcinomas of the head and neck. Curr Opin Oncol 20: 256-263, 2008.

16. Wang R, Chen P, Fan QX and Wang R: Clinical efficacy for the treatment of esophageal cancer with rabdosia rubescens alone and combining with chemotherapy. Life Sci J 4: 22-25, 2007.

17. Wang R and Wang L: Efficacy of Rabdosia rubescens in treating 95 cases with esophageal and gastric cardiac cancer. Cancer Res Prev Treat 11: 86-87, 1994.

18. Kuo LM, Kuo CY, Lin CY, Hung MF, Shen JJ and Hwang TL: Intracellular glutathione depletion by oridonin leads to apoptosis in hepatic stellate cells. Molecules 19: 3327-3344, 2014.

19. Li X, Li X, Wang J, Ye Z and Li JC: Oridonin up-regulates expression of $\mathrm{P} 21$ and induces autophagy and apoptosis in human prostate cancer cells. Int J Biol Sci 8: 901-912, 2012.

20. Zhang CL, Wu LJ, Tashiro S, Onodera S and Ikejima T: Oridonin induced A375-S2 cell apoptosis via bax-regulated caspase pathway activation, dependent on the cytochrome c/caspase-9 apoptosome. J Asian Nat Prod Res 6: 127-138, 2004.

21. Zhou GB, Chen SJ, Wang ZY and Chen Z: Back to the future of oridonin: Again, compound from medicinal herb shows potent antileukemia efficacies in vitro and in vivo. Cell Res 17: 274-276, 2007.

22. Kang N, Zhang JH, Qiu F, Tashiro S, Onodera S and Ikejima T: Inhibition of EGFR signaling augments oridonin-induced apoptosis in human laryngeal cancer cells via enhancing oxidative stress coincident with activation of both the intrinsic and extrinsic apoptotic pathways. Cancer Lett 294: 147-158, 2010.

23. Chou TC and Talalay P: Quantitative analysis of dose-effect relationships: The combined effects of multiple drugs or enzyme inhibitors. Adv Enzyme Regul 22: 27-55, 1984

24. Wang XJ, Li Y, Luo L, Wang H, Chi Z, Xin A, Li X, Wu J and Tang X: Oxaliplatin activates the Keap1/Nrf2 antioxidant system conferring protection against the cytotoxicity of anticancer drugs. Free Radic Biol Med 70: 68-77, 2014.

25. Wang DT, He J, Wu M, Li SM, Gao Q and Zeng QP: Artemisinin mimics calorie restriction to trigger mitochondrial biogenesis and compromise telomere shortening in mice. PeerJ 3: e822, 2015.

26. Siegelin MD, Plescia J, Raskett CM, Gilbert CA, Ross AH and Altieri DC: Networks for therapy of glioblastoma global targeting of subcellular heat shock. Mol Cancer Ther 9: 1638-1646, 2010.

27. Yang D, Torres CM, Bardhan K, Zimmerman M, McGaha TL and Liu K: Decitabine and vorinostat cooperate to sensitize colon carcinoma cells to Fas ligand-induced apoptosis in vitro and tumor suppression in vivo. J Immunol 188: 4441-4449, 2012.

28. Xiong Y, Hannon GJ, Zhang H, Casso D, Kobayashi R and Beach D: p21 is a universal inhibitor of cyclin kinases. Nature 366: 701-704, 1993.

29. Lee WY, Liu KW and Yeung JH: Reactive oxygen speciesmediated kinase activation by dihydrotanshinone in tanshinones-induced apoptosis in HepG2 cells. Cancer Lett 285: 46-57, 2009

30. Salcher S, Hagenbuchner J, Geiger K, Seiter MA, Rainer J, Kofler R, Hermann M, Kiechl-Kohlendorfer U, Ausserlechner MJ and Obexer P: C10ORF10/DEPP, a transcriptional target of FOXO3, regulates ROS-sensitivity in human neuroblastoma. Mol Cancer 13: 224, 2014.
31. Moon DO, Kim MO, Kang CH, Lee JD, Choi YH and Kim GY: JNK inhibitor SP600125 promotes the formation of polymerized tubulin, leading to $\mathrm{G} 2 / \mathrm{M}$ phase arrest, endoreduplication, and delayed apoptosis. Exp Mol Med 41: 665-677, 2009.

32. Ciardiello F and Tortora G: A novel approach in the treatment of cancer: Targeting the epidermal growth factor receptor. Clin Cancer Res 7: 2958-2970, 2001

33. Balin-Gauthier D, Delord JP, Rochaix P, Mallard V, Thomas F, Hennebelle I, Bugat R, Canal P and Allal C: In vivo and in vitro antitumor activity of oxaliplatin in combination with cetuximab in human colorectal tumor cell lines expressing different level of EGFR. Cancer Chemother Pharmacol 57: 709-718, 2006.

34. Park SJ, Kim MJ, Kim YK, Kim SM, Park JY and Myoung H: Combined cetuximab and genistein treatment shows additive anti-cancer effect on oral squamous cell carcinoma. Cancer Lett 292: 54-63, 2010

35. Zhang L, Li XF, Tand L, Zhao YM and Zhou CC: The effects of cetuximab in combination with docetaxel for the acquired resistance to EGFR-TKI in non-small cell lung cancer cells. Tumor 34: 584-590, 2014.

36. Leeman-Neill RJ, Wheeler SE, Singh SV, Thomas SM, Seethala RR, Neill DB, Panahandeh MC, Hahm ER, Joyce SC, Sen $\mathrm{M}$, et al: Guggulsterone enhances head and neck cancer therapies via inhibition of signal transducer and activator of transcription-3. Carcinogenesis 30: 1848-1856, 2009.

37. Wang YY, Lv YF, Lu L and Cai L: Oridonin inhibits mTOR signaling and the growth of lung cancer tumors. Anticancer Drugs 25: 1192-1200, 2014

38. Bao R, Shu Y, Wu X, Weng H, Ding Q, Cao Y, Li M, Mu J, Wu W, Ding $\mathrm{Q}$, et al: Oridonin induces apoptosis and cell cycle arrest of gallbladder cancer cells via the mitochondrial pathway. BMC Cancer 14: 217, 2014.

39. Li D, Wu LJ, Tashiro S, Onodera S and Ikejima T: Oridonin inhibited the tyrosine kinase activity and induced apoptosis in human epidermoid carcinoma A431 cells. Biol Pharm Bull 30: 254-260, 2007.

40. Xiao X, He Z, Cao W, Cai F, Zhang L, Huang Q, Fan C, Duan C, Wang $\mathrm{X}$, Wang $\mathrm{J}$, et al: Oridonin inhibits gefitinib-resistant lung cancer cells by suppressing EGFR/ERK/MMP-12 and CIP2A/ Akt signaling pathways. Int J Oncol 48: 2608-2618, 2016.

41. Selvendiran K, Bratasz A, Tong L, Ignarro LJ and Kuppusamy P: NCX-4016, a nitro-derivative of aspirin, inhibits EGFR and STAT3 signaling and modulates Bcl-2 proteins in cisplatinresistant human ovarian cancer cells and xenografts. Cell Cycle 7: 81-88, 2008.

42. Iwase M, Takaoka S, Uchida M, Yoshiba S, Kondo G, Watanabe H, Ohashi M and Nagumo M: Epidermal growth factor receptor inhibitors enhance susceptibility to Fas-mediated apoptosis in oral squamous cell carcinoma cells. Oral Oncol 44: 361-368, 2008.

43. Kriegs M, Gurtner K, Can Y, Brammer I, Rieckmann T, Oertel R, Wysocki M, Dorniok F, Gal A, Grob TJ, et al: Radiosensitization of NSCLC cells by EGFR inhibition is the result of an enhanced p53-dependent G1 arrest. Radiother Oncol 115: 120-127, 2015.

44. Kang N, Zhang JH, Qiu F, Chen S, Tashiro S, Onodera S and Ikejima $\mathrm{T}$ : Induction of $\mathrm{G}_{2} / \mathrm{M}$ phase arrest and apoptosis by oridonin in human laryngeal carcinoma cells. J Nat Prod 73: 1058-1063, 2010.

45. Gao FH, Hu XH, Li W, Liu H, Zhang YJ, Guo ZY, Xu MH, Wang ST, Jiang B, Liu F, et al: Oridonin induces apoptosis and senescence in colorectal cancer cells by increasing histone hyperacetylation and regulation of p16, p21, p27 and c-myc. BMC Cancer 10: 610, 2010.

46. Hsieh TC, Wijeratne EK, Liang JY, Gunatilaka AL and Wu JM: Differential control of growth, cell cycle progression, and expression of NF-kappaB in human breast cancer cells MCF-7, MCF-10A, and MDA-MB-231 by ponicidin and oridonin, diterpenoids from the chinese herb Rabdosia rubescens. Biochem Biophys Res Commun 337: 224-231, 2005.

47. Tandon M, Salamoun JM, Carder EJ, Farber E, Xu S, Deng F, Tang H, Wipf P and Wang QJ: SD-208, a novel protein kinase D inhibitor, blocks prostate cancer cell proliferation and tumor growth in vivo by inducing G2/M cell cycle arrest. PLoS One 10: e0119346, 2015. 
48. Clerkin JS, Naughton R, Quiney C and Cotter TG: Mechanisms of ROS modulated cell survival during carcinogenesis. Cancer Lett 266: 30-36, 2008.

49. Cheng Y, Qiu F, Ye YC, Guo ZM, Tashiro S, Onodera S and Ikejima T: Autophagy inhibits reactive oxygen species-mediated apoptosis via activating p38-nuclear factor-kappa B survival pathways in oridonin-treated murine fibrosarcoma L929 cells. FEBS J 276: 1291-1306, 2009.

50. Li JP, Yang YX, Liu QL, Pan ST, He ZX, Zhang X, Yang T, Chen XW, Wang D, Qiu JX, et al: The investigational Aurora kinase A inhibitor alisertib (MLN8237) induces cell cycle G2/M arrest, apoptosis, and autophagy via p38 MAPK and Akt/mTOR signaling pathways in human breast cancer cells. Drug Des Devel Ther 9: 1627-1652, 2015.
51. Sánchez-Pérez I, Martínez-Gomariz M, Williams D, Keyse SM and Perona R: CL100/MKP-1 modulates JNK activation and apoptosis in response to cisplatin. Oncogene 19: 5142-5152, 2000.

52. Pereira L, Igea A, Canovas B, Dolado I and Nebreda AR: Inhibition of p38 MAPK sensitizes tumour cells to cisplatininduced apoptosis mediated by reactive oxygen species and JNK. EMBO Mol Med 5: 1759-1774, 2013. 